\title{
Plastic Materials for Modifying the Refractive Index of Contact Lens: Overview
}

ISSN: 2576-8840

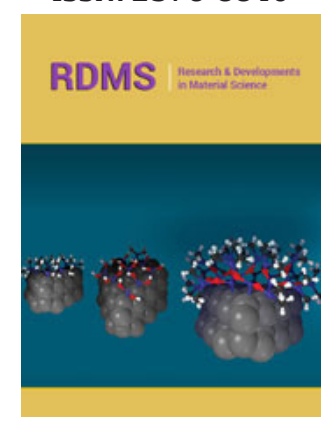

*Corresponding author: Ahmed A AlAmiery, Energy and Renewable Energies Technology Center, Iraq

Submission: 侮 June 24, 2019

Published: 䟱July 25, 2019

Volume 11 - Issue 2

How to cite this article: Lina M S, Ali $\mathrm{H}$ $\mathrm{Al}-\mathrm{H}, \mathrm{Ahmed} \mathrm{A}$ Al-A. Plastic Materials for Modifying the Refractive Index of Contact Lens: Overview. Res Dev Material Sci. 11(2). RDMS.000760.2019.

DOI: 10.31031/RDMS.2019.11.000760

Copyright@ Ahmed A Al-Amiery, This article is distributed under the terms of the Creative Commons Attribution 4.0 International License, which permits unrestricted use and redistribution provided that the original author and source are credited.

\author{
Lina M Shaker ${ }^{1}$, Ali H Al-Hamdani ${ }^{1}$ and Ahmed A Al-Amiery ${ }^{2 *}$ \\ ${ }^{1}$ Laser and Optoelectronics Engineering Department, Iraq \\ ${ }^{2}$ Energy and Renewable Energies Technology Center, Iraq
}

\begin{abstract}
Contact lenses (CLs) are produced from optical polymers which recommended by experts to treat the refractive errors. Researchers are looking for ideal materials in order to improve the CLs optical qualities. This investigation gathers polymeric materials merits to choose the desired pure or doped polymer for the purpose of CLs manufacturing.
\end{abstract}

Methods: high performance CLs can be made of polymers with high transparency nanocomposite because of the need for optical plastic merits such as light weight, transparency, Biocompatibility, the ability to modify its refractive index and abbe number.

Results: $\mathrm{TiO}_{2}$-PMMA and $\mathrm{TiO}_{2}$-PHEMA nanocomposites can be considered the best candidate polymers in CLs fabrication due to its optical properties where it possesses RI higher than 1.52, vd of 30-54, transmittance higher than $92 \%$ and its flexibility and biocompatibility to the human eye tissues.

Conclusion: this article demonstrates the advancement of polymer properties utilized in optical applications focusing on RIs, $v \mathrm{~d}$ and visible light transmittance of the optical plastics that can be utilized in the CLs manufacture or evolution of them.

Keywords: Contact lens; Refractive index; Abbe number; Hybrid materials; Doped polymer

\section{Introduction}

The first material used in contact lenses CLs fabrication was heavy, non-wettable, rough and uncomfortable when wearing them and don't allow the oxygen to through to the cornea, so researchers resorted to employ plastic materials where they started with polymethylmethacrylate (PMMA) that had replaced by another polymer nano-composite s because of unsuitability to wear because it prevent water and oxygen to transmit [1]. Scleral CLs were described by Feinbloom who proposed a scleral CL made of a glass part surrounded by a circular polymeric portion [2] which was developed and amended then by Tuohy [3]. These lenses materials were replaced by optical polymer due to their rough surface and impermeability to water or gases [4]. Several studies have discussed the bioavalabile materials and the CLs brand properties [5,6]. Four main types of CLs are available for both spherical and cylindrical refractive error corrections rigid (hard), soft (hydrogel), frigid gas permeable and hybrid CLs. Rigid CLs made of PMMA [7,8] of RI: vd 1.49:59, light weight, high transparency, high resistant to scratching, a small size Cls and safe to the eye but it does not allow the permeability of water and oxygen (Dk) [9]. In contrast soft lenses are larger size than rigid lenses as illustrated in Figure 1 and made up of polymers that are capable of absorbing water (Figure 2) such as hydroxy-ethylmethacrylate (HEMA). Soft CLs have been patented by Wichterle $[10,11]$, they are more comfortable for longer periods of usage $[12,13]$. CLs made of poly(2-hydroxyethyl) methacrylate (pHEMA) provides great hydrophilicity, but the oxygen permeability is not great $[10,14]$. Rigid gas permeable CLs (RGP) were introduced firstly in 1978. Made of material with molecules that allow the oxygen and carbon dioxide to transmit [15]. It was made up of a silicone-incroported monomer to increase Dk. This process worked well where Chemists have developed these lenses by increasing the proportion of silicon content to increase the surface wettability and lens Dk [16]. Due to RGP CL rigidity, it causes corneal reshaping, which was useful for some post-surgery curing $[17,18]$. Another type of CLs namely hybrid CLs (gas pearmable and HEMA copolymer composition) [19], they are designed in such a way that the central zone made of material of high oxygen permeability surrounded by hydrogel area [20]. 


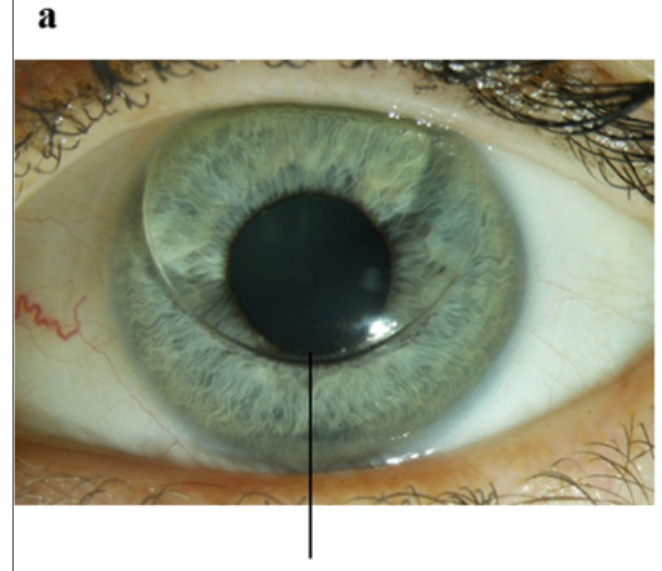

Hard contact lens

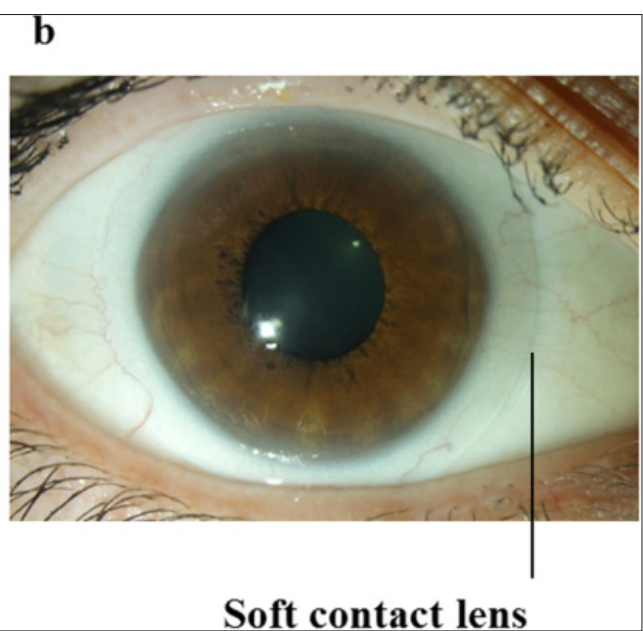

Figure 1: Difference in hard and soft CLs size (a) Hard CL, (b) Soft CL [15].

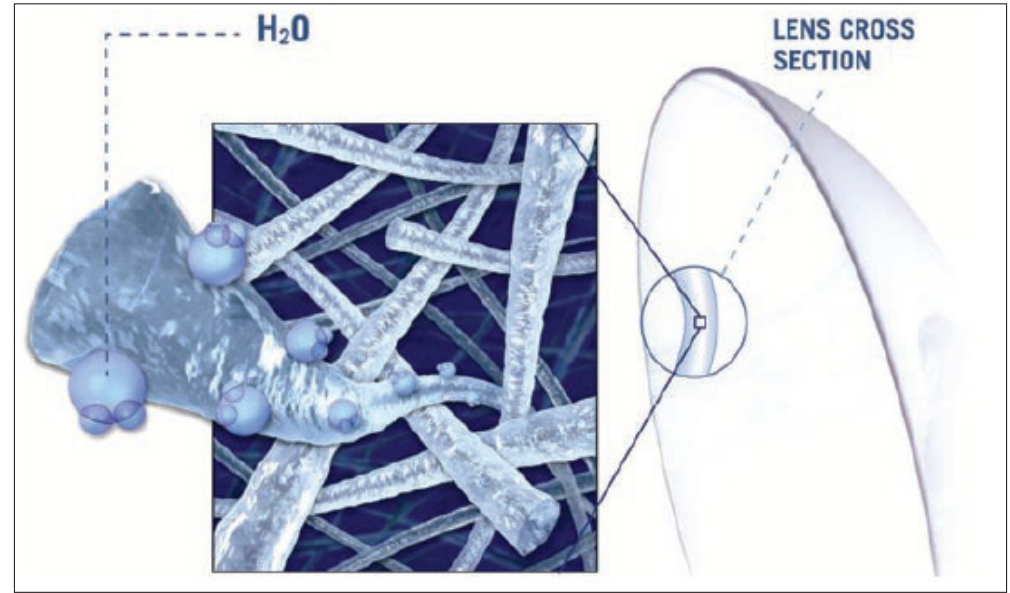

Figure 2: Continuously wetting the material by siloxane molecules which bond and attract the surrounding water.

\section{Optical polymers used to improve the contact lenses optical properties}

Investigation of optical polymers been the subject of different excellent review papers [21]. In the following text we discuss the development and improvement of polymers used in optical applications in terms of permeability, refraction and dispersion properties. A group of researchers has reached several types of optical plastics $[22,23]$ that possess the basic optical characteristics such as RI, vd, light reflectance and transmittance; these polymers have (1.6-1.8) RI; they are Poly(arylene sulfide)s (PAS) (1.66-1.72) [24], transparent thin film made of $\mathrm{TiO}_{2}$ and poly(bisphenol-A and epichlorohydrin) (1.58-1.81) RI [25], polymids derived from paradianhydride, 4,40-[p-sulfonylbis-(phenylenesulfanyl)]-diphthalic anhy-dride (p-DPSDA) (1.7169 to 1.7420) [26], Polythiourethane (1.66-1.68), Polynaphthalen (1.68), Polyether ketone (1.65) and Polyvinyl carbazole (1.68) [27].

Bis(mercaptomethyl)-dithiane (BMMD): In 1997, Tsuyoshi Okubo and coworkers based on polyaddition and polymerization of (bis(mercaptomethyl)-dithiane) (BMMD) with diisocyanates and 2,5-bis (2-thia-3-butenyl)-1,4-dithiane (TBD) in bulk, respectively to obtain a composition of (BMMD) based poly (Salkylcarbamate)s and poly(TBD) have (1.598-1.67) RI range value and $v$ d range of (38.2-34.8) [28]. A developed thermoplastics made of Poly(thioester)s (PTE)s with sulfide and alicyclic series when it synthesized by (BMMD) with 1,3-adaman-tanedicarbonyl dichloride $(\mathrm{ADC})$ to prepare Poly(BMMD/ADC) or cyclohexanedicarbonyl dichloride (CDC) to prepare poly(BMMD/ CDC); the polymer obtained with (RI:vd) of (1.6149:32.1) and (1.6217:30.0), respectively in the vision region [29].

Silicone based polymers: Graded-RI AR coating can improve the optical properties of The used polymer as Ki-Chul [30] suggestion; three thin layers $\mathrm{SiO}_{2}, \mathrm{MgF}_{2}$, and ITO were applied to form a polymer used in ophthalmic lenses; the resultant thin film exhibited (reflactence: lens RI) of (2.6\%:1.60) and (2.7\%:1.67) when using a of polymeric lens [30]. Polydimethylsiloxane (PDMS) (Table 1) of RI (1.375-1.404) and high gas transition has been used in hydrogel CLs that made of silicone as a main material [31]. Two drowbacks of (PDMS) based CLs; they are the high affinity for lipids and this type of lenses is non-wettable which leads to the patient's discomfort when wearing them in terms of vision and comfort $[32,33]$. 
Table 1: Chemical properties of high Dk PDMS.

\begin{tabular}{|c|c|c|c|c|}
\hline Common Name & Polymer Abbrev. & Structure & Chemical Formula & Reference \\
\hline Polydimethyl-siloxane & PDMS & & $\left(\mathrm{C}_{2} \mathrm{H}_{6} \mathrm{OSi}\right) \mathrm{n}$ & [33] \\
\hline
\end{tabular}

The development of silicone hydrogels (long chains of $\mathrm{Si}$ derivates, as seen in Figure 3) has been consumed extensively by CLs manufacturers because it has a role in increasing gas permeability through silicone channels up to four times the gas permeability in conventional hydrogel CLs and maintaining the water content of the CLs [34]. Improvement of this kind of lenses continued by Yuwen and coworkers; they have patented a silicone hydrogel CLs made of a polymarizable silicone and hydrophilic monomors compound [35]. Then Scott and colleagues invented a silicone based high RI rigid gas permeable CL built up from a liquid crystal layer sandwiched between two rigid polymer layers [36]. The two previous CLs patents have an improved gas permeability and are appropriate to the eye tissues. Recently, two CLs made of silicone hydrogel and polyvinylpyrrolidone (PVP) to acquire a smooth water protected CLs valuable for individuals who are experiencing vision issues and working long timespans on PCs [37].

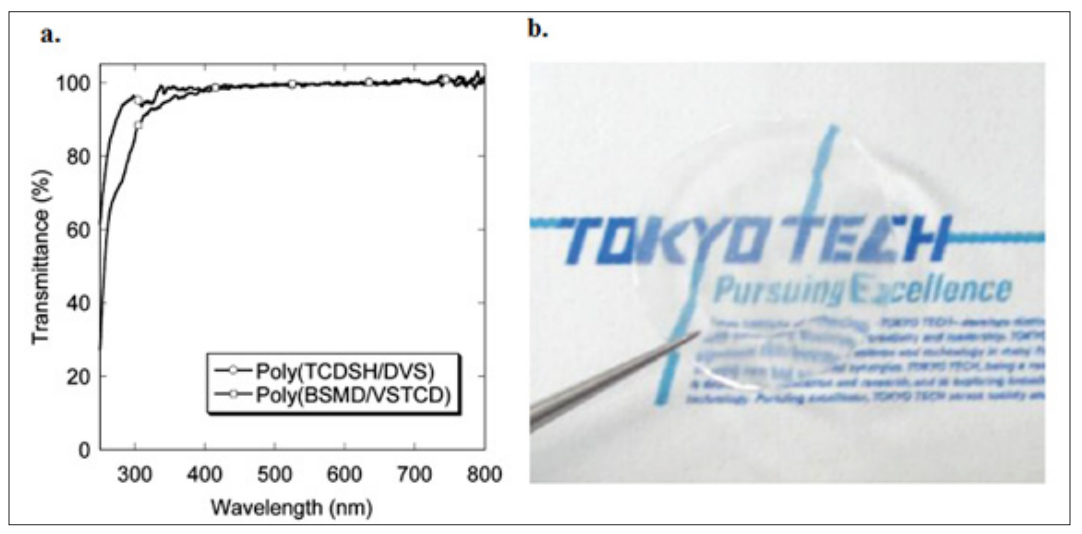

Figure 3: a: transmittance (\%) of p(BSMD/VSTCD) and p(TCDSH/DVS), b: film of p(BSMD/VSTCD) [62].

Polymethacrylates: Include, polymethyl acrylate (PMA), PMMA, HEMA and pHEMA. Hybrid PMMA-dioxide nanocomposites, focusing mostly on $\mathrm{PMMA}_{-} \mathrm{SiO}_{2}$ [38], $\mathrm{PMMA}^{-\mathrm{TiO}_{2}}[39,40]$, $\mathrm{PMMA}_{2} \mathrm{ZrO}_{2}$ [41] (Table 2 \& 3). Trialkoxysilane-capped PMMA-titania (PMMA$\mathrm{TiO}_{2}$ ) hybrid thin film has been prepared with concentration range T0-T100 to obtain RI range of (1.49-2.010) and $v$ d range of (36.514). The results showed that the RI range increased from (1.505 to 1.867) as the tintania concentration increase from 2.9 to $70.7 \mathrm{wt} \%$ while the $v d$ exhibited an opposite behavior [42]. An organic polymer PMMA/ZrO prepared by Otsuka [43] to get polymerized material of above $95 \%$ visible light transmittance and increment in $\mathrm{RI}$ to 1.534 when applying $38.8 \mathrm{wt} \% \mathrm{ZrO}_{2}$ concentration, PMMA/ $\mathrm{ZrO}_{2}$ used to improve optical devices merits [43]. Hybrid PMMA$\mathrm{ZrO}_{2}$ obtained by sol-gel deposition method resulted highly transperancy $\sim 90 \%$ and $1.57 \mathrm{RI}$ at $532 \mathrm{~nm}$ [44]. A great RI boost up to 1.780 obtained by employing nanohybrid material (titaniaPMMA) and transparent thin film in visible region that decreased $v d$ to 31.8 when $\mathrm{TiO}_{2}$ concentration was $40 \mathrm{wt} \%[45,46]$.

Table 2: Chemical structures and formulas of high-RI and high- vd optical polymers used for contact lenses fabrication.

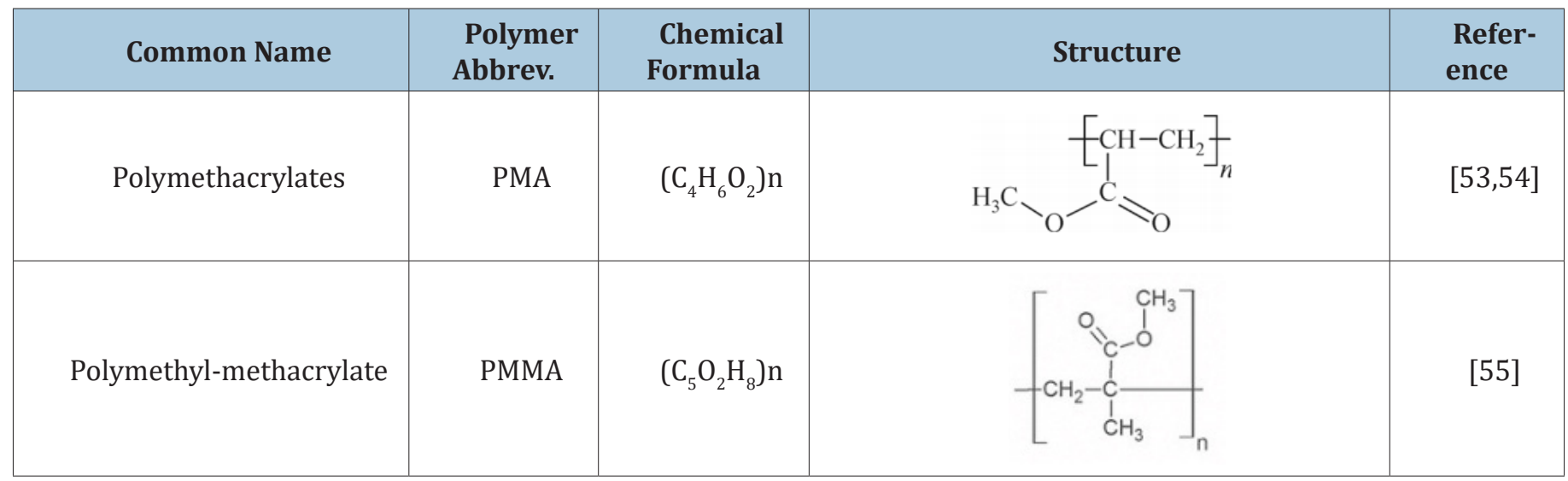




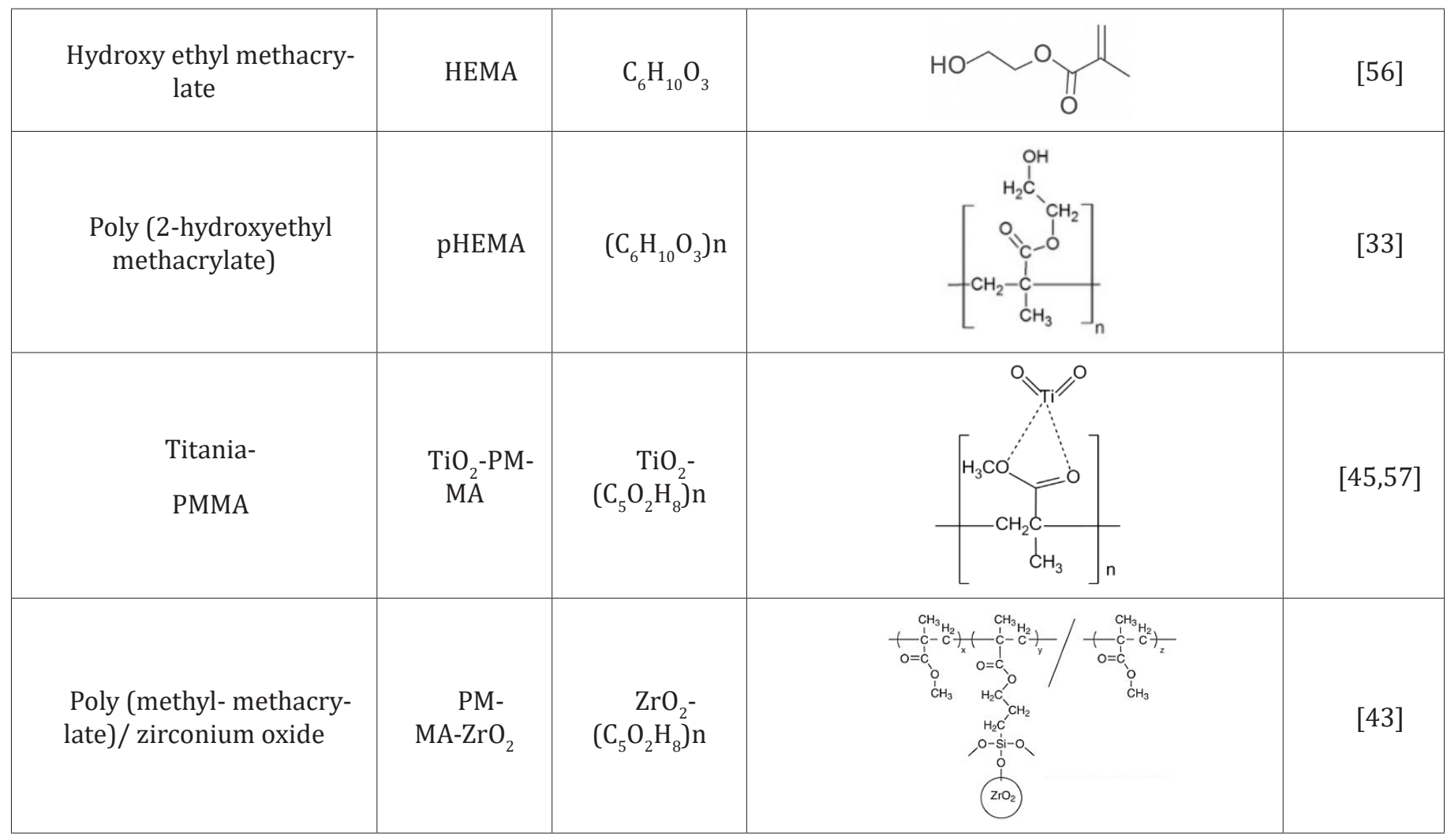

Table 3: The optical characteristics of high-RI and high- vd polymers used in contact lens applications.

\begin{tabular}{|c|c|c|c|}
\hline $\begin{array}{c}\text { Polymer } \\
\text { abbrev. }\end{array}$ & $\begin{array}{c}\text { Transmit- } \\
\text { tance (\%) }\end{array}$ & RI & vd \\
\hline PMA & 90 & 1.4793 & 60 \\
\hline PMMA & 92 & $1.448-1.50$ & 59 \\
\hline HEMA & 97 & 1.453 & - \\
\hline pHEMA & 90 & 1.5119 & 54 \\
\hline $\mathrm{TiO}_{2}$-PMMA & 89 & 1.780 & 31.8 \\
\hline $\mathrm{ZrO}_{2}$-PMMA & 95 & 1.534 & - \\
\hline $\mathrm{TiO}_{2}$-pHEMA & 90 & 1.527 & 54 \\
\hline
\end{tabular}

$\mathrm{TiO}_{2} \mathrm{NP}$ can rise the polymer RI up to 2 and the trasmittance to $90 \%$ through the visible light [47]. PVA-TiO ${ }_{2}$ and $\mathrm{PMMA}^{\mathrm{T}} \mathrm{TiO}_{2}$ nanocopmposites exhibted light transmittance between 80 and $90 \%$ and 1.6 and 2.3 RI [48] as illustrated in Figure 4. Hendrik [49] have investigated a flexible $\mathrm{TiO}_{2}$-pHEMA hydrogel that high transparency in the visible range when it is applied in optical applications, high $v$ d of 54 and $\mathrm{RI}=1.527$ with an excellent transparency $\sim 90 \%$ transmittance $[49,50]$, this nanostructure is therefore an attractive material in optical application that required high visual performance. PVA hydrogel material was the topic of investigation in the 1990s [51]. In addition, polyethylene glycol (PEG) surface coating has invented by Imafuku to improve the Si-based CLs hydrophilicity [52]. Low cost, high wettability and bioavailability
PVA hydrogel make it relatively important to hydrogel CLs industry compared with silicone and HEMA hydrogels [53-57].

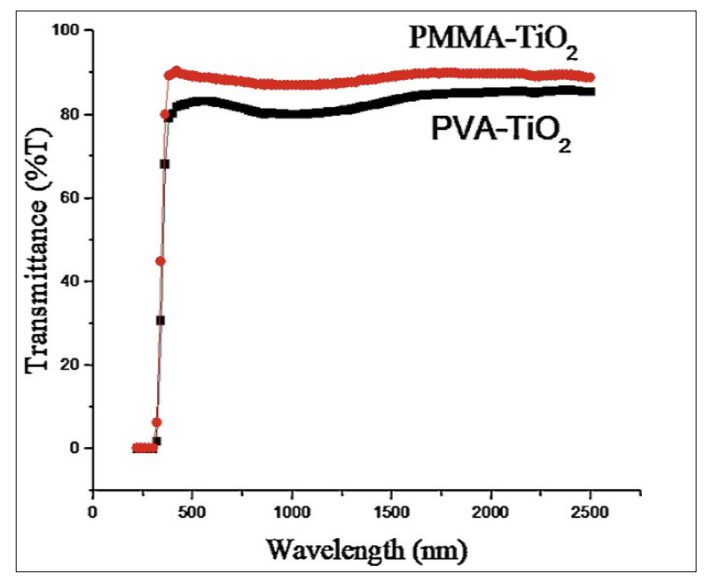

Figure 4: Transmittance (\%) of PVA- TiO2 and PMMA-TiO2 nanocomposite films [48].

Polycarbonate (PC): In 2009 The studies concerned to modefy the lightweight polycarbonate (PC) lenses (clarity 90\%) from diethylene glycol di(allyl carbonate) (DEGDAC) based (polythiol) (Table 4), the resultant (PC) of improved RI (1.49-1.66) and decreased $v \mathrm{~d}$ range between (26-37) [58]. Five decades ago, polycarbonates were commonly used in spectacle lenses fabrication which holds high scratching resistance, but it is hard to use in CLs, despite the trails that were done to develop them. In 2018, Halah A [59] was tested Allyl carbonate polymer material as CL [59], which is usually known as CR-39. The CR-39 characterized by RI of 1.49 and $v$ d of 58-59. 
Table 4: Chemical structure and formula of DEGDAC.

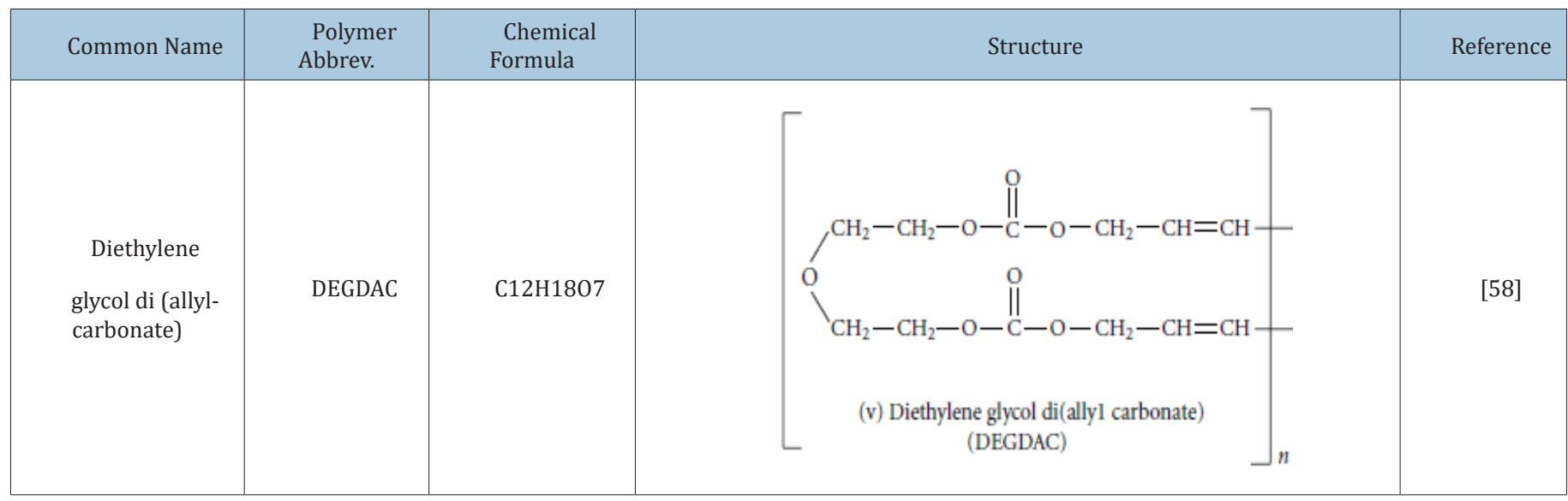

Sulfur-containing polymers: Sulfur compounds such as polysulfide, polythiol, episulfide groups are used in CLs fabrication due to their optical properties. Polymers containing a sulfur atom such as 2-(tricycle-[5,2,1,0.6]-3-decenylthio) ethyl methacrylate (DTEMA) appears high transparency (transmittance 91\%) and have a RI and $v$ d of 1.557 and 47.4, respectively. When it converted into a copolymer, the $v \mathrm{~d}$ value degraded as the RI increased, according to the added polymer and its monomers concentration. When bromine DTEMA/ bromine 2,2-bis(3,5-dibromo-4-methacryloyloxyethoxy-phenyl) propane $\left(\mathrm{Br}_{2} \mathrm{DTEMA} / \mathrm{Br}_{4} \mathrm{BMEPP}\right)$ copolymer is prepared RI, vd and transmittance have reached to $1.608,30.4$ and $90 \%$, respectively [60]. In 2010 by Yasuo [61] and researchers have improved the optical properties of copoly (thioether-sulfone) s (Figure 5) with a polymeric composition of sulfide, sulfone, and alicyclic, the later materials were equipped by copolymerization technique of 2,5-bis(sulfanylmethyl)-1,4-dithiane (BMMD) and cyclohexane-1,4-dithiol (CHDT) with divinyl sulfone (DVS) based on the Michael polyaddition the resultant polymer called Poly (BMMD/CHDT-DVS) had (1.6512-1.6022) RI range and (42.6-50.6) $v d$ range [61].

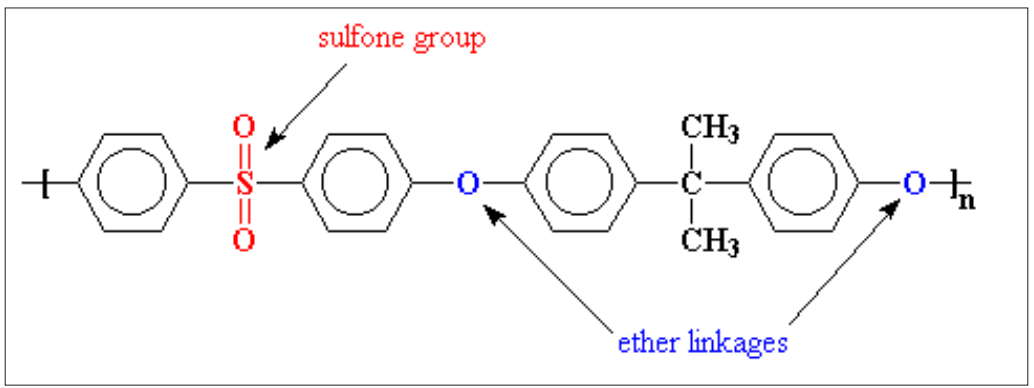

Figure 5: PES get their name because of existence of sulfone groups and ether groups in their back bone chain.

Due to Suzuki and colleagues proposal, a flexible, highly transmittance thermoplastic disulfanyl-tricyclodecane/ divinyl sulfone $\mathrm{p}(\mathrm{TCDSH} / \mathrm{DVS})$ of $(\mathrm{n}=1.6052$ and $v \mathrm{~d}=48.0)$ and 2,5-bis(sulfanyl-methyl)-1,4-dithiane bis(vinylsulfone) tricyclo decane $\mathrm{p}(\mathrm{BSMD} / \mathrm{VSTCD})$ of $(\mathrm{RI}=1.6228$ and $v \mathrm{~d}=45.8)$ [62]. Tapaswi [63] and coworkers have reached a flexible transparent film made of 2,2'-Bis(thiophenyl)-benzidine (BTPB) and 2,2'-bis(4chlorothio-phenyl)-benzidine monomers (BCTPB) were prepared and synthesized to achieve the aromatic polyimide (BPDA/BCTPB) of (1.7282) RI and tansmittivity of 83\% [63]. The gained film useful in lens materials other optical applications required high transparency and flexibility (Figure 3).

Bin [64] were utilized Alumina nanoparticles (NPs) to get low dispersion materials; they prepared 1,3-bis(2-hydroxyethylsulfonyl)-2-propanol/2,2'-thiodiglycolic acid/ alumina (BHESP/ TDGA/Al) which provided (RI=1.580, vd=55) and 2,2' -thiodiglycolic acid/ phthalic acid/ alumina (BHESP/PA/Al) of $(\mathrm{RI}=1.631, v \mathrm{~d}=53)$ nano-composites [64]. Carbonylsulfide (COS), eugenol-based glycidyl ether (EGE) and guaiacol-based glycidylether (GGE) were used by Zhang and coworkers to prepare the copolymers EGE/ COS, GGE/COS, and EGE/ GGE/COS; these polymers appeared high$\mathrm{RI}>1.58$ and $v d$ range of (32.5 - 40.4) [65]. Tang and a group of researchers have intended a novel high-RI (1.707) and transparent (transmissivity of 89\%) polymer named episulfide-thiol has prepared from episulfide synthesis which in turn is derived from 9,9-bis(4-glycidyloxyphenyl)fluorine (BGF) and 4,4-thiodibenzenethiol (TBT) to get the high optically transparent polymer episulfide-thiol [66].

Zinc based polymers: According to Sung [67], UV-block hydrogel CLs (78 90\% transmittance in visible region) can be produced by inserting Zinc oxide ( $\mathrm{ZnO}$ ) NP in addition to vinyl pyridine to MMA, HEMA and N-vinylpyrrolidone (N-VP) blend 
to take out (1.429 1.450) RI polymer from this polymerization process [67]. A group of researchers have come up with hydrogel nano-composite a chain of ZnS/PVP/PDMAA (Table 5), (30-60) wt $\%$ concentration of $\mathrm{ZnS} \mathrm{NP}$ has exploited to realize a transparent nano-composite, (1.58-1.70) and (1.38-1.46) RI in the dry and hydrated states, respectively [68].

Table 5: Chemical characterstics of $\mathrm{ZnS} / \mathrm{PVP}$.

\begin{tabular}{|c|c|c|c|}
\hline Common Name & Polymer Abbrev. & $\begin{array}{c}\text { Chemical For- } \\
\text { mula }\end{array}$ & $\begin{array}{c}\text { Structure } \\
\text { ence }\end{array}$ \\
\hline $\begin{array}{c}\text { Zinc sulfide/ poly (N-vinyl- pyr- } \\
\text { rolidone) }\end{array}$ & $\mathrm{ZnS} / \mathrm{PVP}$ & $\mathrm{ZnS}-\left(\mathrm{C}_{6} \mathrm{H}_{9} \mathrm{NO}\right) \mathrm{n}$ \\
\hline
\end{tabular}

Incorporation of PVP and moisturizing agents into Soft CLs has changed the surface wettibilty. These agents may result increased comfort and enhanced the stability of tear film [69,70]. Zinc also used extensively to prepare NP antibacterial coatings applied on CLs surfaces [71], also the hybrid ZnO/PMMA polymer provides a colorless film of (1.6) RI which can be considered useful in such applications [72]. ZnS NPs have employed to obtain polymerized nano-composite grafted with $\mathrm{ZnS}$, where a copolymerization process with a mixture of $\mathrm{N}, \mathrm{N}$-dimethylacrylamide (DMA) and
HEMA (Table 5) or glycidyl methacrylate (GMA) or methyl methacrylate (MMA), the produced polymer exhibits a trassmitance above $92 \%$ in visible region and RI range of (1.652 and 1.751) after changing ZnS concentration from 33.4 to $50.3 w t \%$ [73]. Then Peili [74] has suggested a ZnS-inorganic hydrogel CLs (Figure 6) by copolymerizing ZnS-polymerizable group with HEMA monomer to get RI with a range of (1.38 -1.45) as the $\mathrm{ZnS}$ concentration varied from (30 to 60$) w t \%[74,75]$.

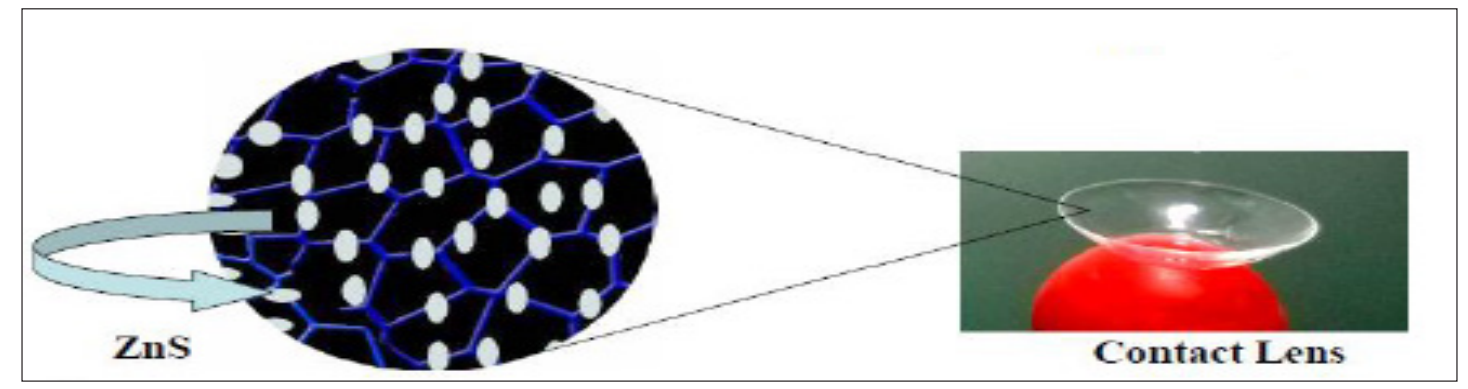

Figure 6: ZnS-inorganic hydrogel CL [74].

Poly (Glycidyl Methacrylate) (PGMA): High RI can be achieved by Poly(glycidyl methacrylate) (PGMA) (Table 6) modification as Huinan [76] proposal; this is done by using a PGMAs selenide chain, The concentration of selenium has been varied by a certain percentages, the resultant polymer has RI of (1.719) and $v d$ decreased to (11.3) [76]. Optical Polymers helped researchers to improve CLs performance as Jung [77] and his colleague did for PDMS-CLs [77]. They have developed it for the purpose of preventing its adsorption of protein by submerging the lens in deby poly(ethylene glycol) meth-acrylate (PEGMA) [78]. PEGMA is a low-cost polymer and it is easy to incorporate with other chemical components. Industrialization aspects need to be considered to achieve the required configurations in a new CLs generation, where, increasing PEGMA concentration in silicone hydrogels affected the lens properties such as increasing brittleness above $20 \%$.

Table 6: PGMA chemical structure and formula.

\begin{tabular}{|c|c|c|c|c|}
\hline Common Name & Polymer Abbrev. & $\begin{array}{c}\text { Chemical } \\
\text { Formula }\end{array}$ & Structure \\
\hline Poly (glycidyl methacrylate) & PGMA & & $\left(\mathrm{C}_{7} \mathrm{H}_{10} \mathrm{O}_{3}\right) \mathrm{n}$ \\
\hline
\end{tabular}


Polymers based on phosphorus: In order to rise up the RI of phosphorus compounds, Phosphonic dichlorides and diols used in synthesis with polyphosphonate; the gained polymers characterized by high optical transparency, high RI (1.60-1.65) and vd of (22.429.9) [79]. Ryoyu [80] have developed novel high RI materials (1.626-1.687) and vd (21.3-27.5) consisting of poly(thiophosphonate)s, which were synthesized by polycondensation of phenylthio-phosphonic dichloride with various bisphenols [80].

\section{Conclusion}

Initially at least, rigid CLs are providing much less comfort than soft lenses. There were several attempts to use RGP CLs for extended wear. The success of RGP CLs due to their rigidity, causing corneal reshaping, which was beneficial for some post-surgery treatment. The main contraindications for both hard and soft CLs are the allergy and dry eye. Selecting a suitable Polymers and material types that can be used in CL manufacture must be characterized by specific optical properties such as oxygen transmissivity, adaptability with human eye tissues, high RI and high vd gas permeability, high transparency within the visible spectrum and scratching resistance to get the desired image quality when wearing them. Doping with $\mathrm{TiO}_{2}$ NPs satisfies the requirements that must be met in the desired plastic polymer such as $\mathrm{TiO}_{2}$-PMMA and $\mathrm{TiO}_{2}$-PHEMA optical polymers to improve the CLs optical quality.

\section{References}

1. Weissman B (2006) Clinical practice guidelines: Care of the contact lens patient. ( $2^{\text {nd }}$ edn), Am Optom Assoc, p. 46.

2. Melissa B, Lynette JK (2017) History of scleral lenses. In: Contemporary Scleral Lenses: Theory and Application, Bentham Science Publishers, UAE, p. 17.

3. Touhy KM (1950) Contact lens. U.S. Patent 2510438.

4. Owuagwu F (2003) Contact lens wear and the oxygen issue: A review. J Niger Optom Assoc.

5. Caló E, Khutoryanskiy VV (2015) Biomedical applications of hydrogels: A review of patents and commercial products. Eur Polym J 65: 252-267.

6. Vidal-Rohr M, Wolffsohn JS, Davies LN, Cerviño A (2018) Effect of contact lens surface properties on comfort, tear stability and ocular physiology. Contact Lens Anterior Eye 41(1): 117-121.

7. Lee DA, Eve HJ (1999) Clinical guide to comprehensive ophthalmology. Thieme, p. 70.

8. Hom MM, Bruce AS (2006) Manual of contact lens prescribing and fitting. Elsevier Butterworth-Heinemann, UK, p. 133.

9. Sultanova N, Kasarova S, Nikolov I (2009) Dispersion properties of optical polymers. Acta Phys Pol A 116(4): 585-587.

10. Wichterle 0 (1960) Hydrophilic gels for biological use. Nature 185: 117118.

11. Wichterle 0 (1965) Cross-linked hydrophilic polymers and articles made therefrom.

12. Tanaka K, Takahashi K, Kanada M, Kanome S, Nakajima T (1979) Copolymer for soft contact lens, it's preparation and soft contact lens made thereof.

13. Dahl A, Brocks E (1978) The use of continuous-wear silicone contact lenses in the optical correction of aphakia. Am J Ophthalmol 85(4): 454461.
14. Tighe BJ (1976) The design of polymers for contact lens applications. Br Polym J, pp. 71-77.

15. Manicam C (2018) Proteomics unravels the regulatory mechanisms in human tears following acute renouncement of contact lens use: A comparison between hard and soft lenses. Sci Reports Nat 11526: 1-15.

16. Yokota M, Goshima T, Itoh S (1992) The effect of polymer structure on durability of high Dk gas permeable materials. J Br Contact Lens Assoc 15(3): 125-129.

17. Vincent SJ, Alonso-Caneiro D, Collins MJ (2014) Corneal changes following short-term miniscleral contact lens wear. Cont Lens Anterior Eye 37(6): 461-468.

18. Lai YC, Nonaffine JA (2008) Rigid gas permeable lens material.

19. Edward BS, Barry WA (2005) Clinical contact lens practice. Lippincott Williams \& Wilkins, USA, p. 475.

20. Schifrin LG, Rich WJ (1984) The contact lens industry: structure, competition, and public policy. DIANE Publishing, USA, pp. 15-17.

21. Stephen C, Fang F (2019) Contact lens materials: A materials science perspective. Materials (Basel)12(2): 1-36.

22. Suri G (2010) Challenges in preparation of metal-containing nanocomposites; Dispersion of titanium into plastics. E-Polymers.

23. Park SK (2014) Triethylene glycol-titanium oxide hydrate hybrid films with high refractive index and surface evenness. J Mater Chem C 2(22): 4468-4475.

24. SS, Takata T (2007) Synthesis and property of poly (arylene sulfone) s Containing 9, 9-Diarylfluorene moiety in the main chain. Polym Journal 39(7): 731-736.

25. Nakayama N, Hayashi T (2007) Preparation and characterization of $\mathrm{TiO}_{2}$ and polymer nanocomposite films with high refractive index. J Appl Polym Sci 105: 3662-3672.

26. Liu JG, Nakamura Y, Suzuki Y, Shibasaki Y, Ando S, et al. (2008) Synthesis highly refractive and transparent polyimides derived from 4,4'-[m-sulfonylbis(phenylenesulfanyl)]diphthalic anhydride and various sulfur-containing aromatic diamines. Macromolecules 40(22): 7902-7909.

27. Tyagi M, Suri G, Chhabra P, Seshadri G, Malik A, et al. (2009) Novel way of making high refractive index plastics; metal containing polymers for optical applications. e-Polymers (100): 1-18.

28. Okubo T, Kohmoto S, Yamamoto M (1997) Properties of polymers comprising 1, 4-Dithiane-2, 5-Bis (thiomethyl) group. J Appl Polym Sci 68: 1791-1799.

29. You N, Higashihara T, Yasuo S, Ando S, Ueda M (2010) Synthesis of sulfurcontaining poly (thioester) $\mathrm{s}$ with high refractive indices and high Abbe numbers. Polym Chem 1: 480-484.

30. Kim KC (2015) Effective graded refractive-index anti-reflection coating for high refractive-index polymer ophthalmic lenses. Mater Lett 160: 158-161.

31. Ratner B (1989) Biomedical applications of synthetic polymers, in comprehensive polymer science: Specialty polymers \& polymer processing. In: Agganval SL (Ed.), Pergamon Press, New York, USA, p. 685.

32. Efron $N(2010)$ Contact lens practice. ( $2^{\text {nd }}$ edn), Elsevier Limited, Amsterdam, Netherlands, pp. 5-6.

33. Wypych G (2016) Handbook of polymers. ( $\left.2^{\text {nd }} e d n\right)$, Chem Tec Publishing, Toronto, Ontario, Canada, pp. 340-467.

34. Méijome JMG, Pérez GJ, Fernandes PRB, Ferreira DPL, Mollá S, et al. (2014) Silicone hydrogels materials for contact lens applications. Concise Encycl High Perform Silicones, pp. 293-308. 
35. Liu Y, Siddiqui S, Ji Y, Ge J (2017) Silicone hydrogel contact lenses. US patent, $9625616 \mathrm{~B} 2$.

36. Kennedy S, Linhardt JG, Diciccio A (2018) Cast moldable, high ri, rigid, gass permeable polymer formulations for an accommodating contact lens. US Patent, $0088352 \mathrm{~A} 1$

37. Schafer J, Reindel W, Steffen R, Mosehauer G, Chinn J (2018) Use of a novel extended blink test to evaluate the performance of two polyvinylpyrrolidone- containing, silicone hydrogel contact lenses. Dovepress J Clin Ophthalmol 12: 819-825.

38. Soni G, Srivastava S, Soni P, Kalotra P, Vijay YK (2018) Optical, mechanical and structural properties of $\mathrm{PMMA} / \mathrm{SiO}_{2}$ nanocomposite thin films. Mater Res Express 5(1).

39. Maeda S, Fujita M, Idota N, Matsukawa K, Sugahara Y (2016) Preparation of transparent bulk $\mathrm{TiO}_{2} / \mathrm{PMMA}$ hybrids with improved refractive indices via an in-situ polymerization process using $\mathrm{TiO}_{2}$ nanoparticles bearing PMMA chains grown by surface-initiated atom transfer radical polymerization. ACS Appl Mater Interfaces 8(50): 34762-34769.

40. Benhabiles O, Galiano F, Marino T, Mahmoudi H, Lounici H, et al. (2019) Preparation and Characterization of $\mathrm{TiO}_{2}-\mathrm{PVDF} / \mathrm{PMMA}$ blend membranes using an alternative non-toxic solvent for UF/MF and photocatalytic application. Molecules 24(4): 1-20.

41. Gad MM, Abualsaud R, Rahoma A, Al-Thobity AM, Al-Abidi KS, et al. (2018) Effect of zirconium oxide nanoparticles addition on the optical and tensile properties of polymethyl methacrylate denture base material. Int J Nanomedicine 13: 283-292.

42. Lee L, Chen W (2001) High-refractive-index thin films prepared from trialkoxysilane-capped poly (methyl methacrylate)-titania materials. Chem Mater 15: 1137-1142.

43. Otsuka T, Chujo Y (2010) Poly (methyl methacrylate) (PMMA)-based hybrid materials with reactive zirconium oxide nanocrystals. Polym J 42(1): 58-65.

44. Alvarado-beltran CG, Almaral-Sanchez JL, Ramırez-Bon R (2015) Synthesis and properties of PMMA-Z $\mathrm{Zr}_{2}$ organic-inorganic hybrid films. J Appl Polym Sci 132(44): 1-7.

45. Yuwono AH (2004) Controlling the crystallinity and nonlinear optical properties of transparent $\mathrm{TiO}_{2}$-PMMA nanohybrids. J Mater Chem 14: 2978-2987.

46. Tao P (2011) Refractive index engineering of polymer nanocomposites prepared by end-grafted polymer chains onto inorganic nanoparticles. Mater Res Soc 1359: 163-168.

47. Cai B, Sugihara O, Elim HI, Adschiri T, Kaino T (2011) A novel preparation of high-refractive-index and highly transparent polymer nanohybrid composites. Appl Phys Express 4(9): 1-3.

48. Sugumaran S, Bellan CS (2014) Transparent nano composite PVA-TiO and PMMA-TiO 2 thin films: Optical and dielectric properties. Optik 125(18): 5128-5133.

49. Reinhardt HM, Recktenwald D, Kim HC, Hampp NA (2016) High refractive index $\mathrm{TiO}_{2}$-PHEMA hydrogel for ophthalmological applications. J Mater Sci 51(22): 9971-9978.

50. Hampp N, Dams C, Badur T, Reinhardt H (2017) $\mathrm{TiO}_{2}$ Nanoparticles for enhancing the refractive index of hydrogels for ophthalmological applications. Proc SPIE 10078: 100780I.

51. Kita M, Ogura Y, Honda Y, Hyon SH, Cha WI, et al. (1990) Evaluation of polyvinyl alcohol hydrogel as a soft contact lens material. Graefe's Arch Clin Exp Ophthalmo 228(6): 533-537.

52. Imafuku S (2014) Silicone hydrogel soft contact lens having wettable surface. US Patent, 0362339.

53. Speight JG (2005) Lange' S handbook of chemistry, (16 ${ }^{\text {th }}$ edn), pp. 2735 2807.
54. Shirota Y, Kageyama H (2013) Encyclopedia of polymeric nanomaterials. Springer-Verlag Berlin Heidelberg, Germany, p. 4.

55. Lucia Ronchi (2012) Atti della fondazione giorgio ronchi. Catalyst, p. 736.

56. Jha GS, Seshadri G, Mohan A, Khandal RK (2007) Development of high refractive index plastics. e-Polymers 7(1): 1-25.

57. Fujita M, Idota N, Matsukawa K, Sugahara Y (2015) Preparation of oleyl phosphate modified $\mathrm{TiO}_{2} /$ Poly (methyl methacrylate) hybrid thin films for investigation of their optical properties. J Nanomater 297197: 1-7.

58. Suri G, Jha GS, Seshadri G, Khandal RK (2009) Modification of low refractive index polycarbonate for high refractive index applications. Int J Polym Sci 836819: 1-8.

59. Al-hamdani AH, Halah AH (2018) Effect of field of view and iris pupil diameter on the quality of retinal image with allyl carbonate (CR-39) polymer contact lenses. IOP Conf Ser Mater Sci Eng 454(1): 454012081.

60. Matsuda T, Funae Y, Yoshida M, Yamamoto T, Takaya T (2000) Optical material of high refractive index resin composed of sulfur-containing aliphatic and alicyclic methacrylates. J Appl Polym Sci 76(1): 45-49.

61. Suzuki Y, Higashihara T, Ando S, Ueda M (2010) Synthesis of amorphous copoly (thioether sulfone) s with high refractive indices and high Abbe numbers. Eur Polym J 46(1): 34-41.

62. Suzuki Y, Higashihara T, Ando S, Ueda M (2012) Synthesis and characterization of high refractive index and high Abbe's number poly (thioether sulfone) $\mathrm{s}$ based on tricyclo [5.2.1.0 $\left.0^{2,6}\right]$ decane moiety. Macromolecules 45(8): 3402-3408.

63. Tapaswi PK, Choi MC, Jeong KM, Ando S, Ha CS (2015) Transparent aromatic polyimides derived from thiophenyl-substituted benzidines with high refractive index and small birefringence. Macromolecules 48(11): 3462-3474

64. Cai B, Kaino T, Sugihara O (2015) Sulfonyl-containing polymer and its alumina nanocomposite with high Abbe number and high refractive index. Opt Mater Express 5(5): 1210-1216.

65. Hu LF, LiY, Liu B, Zhang YY, Zhang XH (2017) Alternating and regioregular copolymers with high refractive index from COS and biomass-derived epoxides. RSC Adv 7(78): 49490-49497.

66. Tang Y, Pina-Hernandez C, Niu Q, Nie J, Cabrini S (2018) A novel highrefractive index episulfide-thiol polymer for nanoimprinting optical elements. J Mater Chem C 6(32): 8823-8831.

67. Sung A, Kim T (2013) Physical properties of ophthalmic hydrogel polymer containing zinc oxide nanoparticles. J Chosun Nat Sci 6(2): 7681.

68. Zhang Q Su K, Chan-park MB, Wu H, Wang D, et al. (2014) Development of high refractive ZnS/ PVP/PDMAA hydrogel nanocomposites for artificial cornea implants. Acta Biomater 10(3): 1167-1176.

69. Nichols J (2007) A look at lubricating agents in daily disposables. Contact Lens Spectr 22(1): 22.

70. Nick J, Winterton L, Lally J (2006) Lubricating lens focuses on patient comfort. Contact Lens Spectr 21(1): 40-41.

71. Tuby R, Gutfreund S, Perelshtein I, Mircus G, Ehrenberg M, et al. (2016) Fabrication of a stable and efficient antibacterial nanocoating of zn-cuo on contact lenses. Chem Nano Mat 2(6): 547-551.

72. Wang Z, Lu Z, Mahoney C, Yan J, Ferebee R, et al. (2017) Transparent and high refractive index thermoplastic polymer glasses using evaporative ligand exchange of hybrid particle fillers. ACS Appl Mater Interfaces 9(8): 7515-7522.

73. Xu J, Zhang Y, Zhu W, Cui Y (2018) Synthesis of polymeric nanocomposite hydrogels containing the pendant zns nanoparticles: approach to higher refractive index optical polymeric nanocomposites. Macromolecules 51(7): 2672-2681. 
74. Zhao P, Xu J, Zhang Y, Zhu W, Cui Y (2018) Polymerizable-group capped $\mathrm{ZnS}$ nanoparticle for high refractive index inorganic-organic hydrogel contact lens. Mater Sci Eng C Mater Biol Appl 90: 485-493.

75. Zhang Q, Shing Mei, Beuerman R, Judeh Z, Chan M, et al. (2013) Development of optically transparent ZnS/Poly (vinylpyrrolidone) nanocomposite films with high refractive indices and high abbe numbers. J Appl Polym Sci 129(4): 1793-1798.

76. Jiang H, Pan X, Li N, Zhang Z, Zhu J, et al. (2016) Selenide-containing high refractive index polymer material with adjustable refractive index and Abbe's number. React Funct Polym 111: 1-6.

77. Lin CH, Yeh YH, Lin WC, Yang MC (2014) Novel silicone hydrogel based on PDMS and PEGMA for contact lens application. Colloids Surf B Biointerfaces 123: 986-994.
78. Chen JS, Liu TY, Tsou HM, Ting YS, Tseng YQ et al. (2017) Biopolymer brushes grown on PDMS contact lenses by in situ atmospheric plasmainduced polymerization. J Polym Res 24(5).

79. Macdonald EK, Lacey JC, Ogura I, Shaver MP (2016) Aromatic polyphosphonates as high refractive index polymers. Eur Polym J 87: 14-23.

80. Hifumi R, Tomita I (2018) Synthesis and high refractive index properties of poly(thiophosphonate)s. Polym J 50(6): 467-471. 